\title{
SPATIAL BIODIVERSITY MODEL TO CHARACTERIZE BIOLOGICAL DIVERSITY USING R STATISTICAL COMPUTING ENVIRONMENT FOR NEPAL HIMALAYA
}

\author{
R. Silwal ${ }^{1,2, *, \text { A. } \text { Roy }^{2}, \text { H. Karnatak }}{ }^{2}$, R. B. Thapa ${ }^{1}$ \\ ${ }^{1}$ International Centre for Integrated Mountain Development, Khumaltar, Lalitpur, 44700, Nepal - (Ramesh.Silwal, \\ Rajesh.Thapa)@icimod.org \\ ${ }^{2}$ Indian Institute of Remote Sensing, 4 Kalidas Road, Dehradun, 248001, Uttarakhand, India - (arijitroy, harish)@iirs.gov.in
}

Commission V, WG V/7 \& Commission IV, WG IV/6

KEY WORDS: Multi-criteria Decision Analysis, Spatial Biodiversity Model, Biodiversity Characterization

\begin{abstract}
:
Biodiversity characters of the landscape provide basis of prioritizing the sites in conservation effort. There is an urgent need for rapid assessment of existing biodiversity using state-of-art tools and technologies at large scale. The purpose of the study is to model and prioritize biological richness based on multi-criteria decision analysis (MCDA) for conservation priority and management planning. Vegetation type map for year 2017 was developed for generation of various landscape indices e.g. fragmentation, patchiness, porosity, juxtaposition etc. The Spatial Biodiversity Model (SBM) prepared for similar landscape of Uttarakhanda, India which is scale, resolution and location independent for spatial biodiversity richness modelling was executed in R programming platform. Satellite data, non-spatial data and ancillary data were used to generate Biological Richness (BR) map which is categorized into 4 classes as low, moderate, high and very high (biodiversity rich) including non-forest area to quantify BR area. The result shows that largest area is under very high biological richness class followed by high, moderate and low BR area. Overall accuracy and Kappa Statistics of LULC/vegetation type classification is $82.61 \%$ and 0.8013 respectively. The spatial regression analysis for final output validation has been made with ground based species diversity data where $\mathrm{R}^{2}$ value for Shannon-Wiener index and Margalef's diversity index are 0.64 and 0.56 respectively. The results also re-emphasize the role of geospatial techniques in the quick appraisal of predicting biological richness. The study result is applicable in systematic inventory of biological resources, land use planning, conservation prioritization and policy support.
\end{abstract}

\section{INTRODUCTION}

Increasing human intervention and excessive exploitation of resources have resulted in great changes and provide alarming signals of accelerated biodiversity loss (Roy and Tomar 200). Due to immense pressure on biological resources, mainly to drive the global economic engine, the global biodiversity is under tremendous threat (Gordon et al., 2011; Kersebaum et al., 2015). Climate change impacts are becoming increasingly evident in the Himalayan region (Shrestha et. al., 2012, Zomer et. al., 2014) which has profound implications for mountain communities (Ebi et. al., 2007), its biodiversity including major non-timber forest plants (Chitale et. al., 2018), ecosystem services (Beniston 2003), water resources (Immerzeel et. al., 2010), agricultural systems (Maikhuri et. al., 2001), and both regional and global climate processes. In the present scenario, with the extinction rate in most areas overtaking the process of biodiversity inventory, there is an urgent need for rapid assessment of biodiversity which is robust and is replicable over large area (Sing et. al., 2017). Landscape ecology seeks to understand the ecological functions of larger areas and hypothesizes that spatial arrangement of ecosystems, habitats or communities has ecological implications (Romme, Knight, 1982; Turner, 1987). Distribution of biodiversity is mainly a function of climatic conditions, edaphic and topographic regimes which are perfect for speciation (Beltran et al., 2014; Zhai et al., 2015). The mosaic of natural areas and land use provide the scenario for loss of the endemic species due to reduced population size in the remnant patches as well as create conditions for exotic species to invade new areas (Prasad et al., 2010; Roy et al., 2016). This provides a unique opportunity to use the land use ad land cover (LULC) and the geographical variability of biodiversity to model the spatial distribution of the biodiversity.

There have been numerous approaches (Behera, Roy, 2010; Orsi et al., 2011; Wilson et al., 2016, Myers et al., 2000; Roy, Tomar, 2000) to quantify the biological diversity using empirical approaches like biodiversity hotspots. Recently, the application of general ecological model (Harfoot et al., 2014; Yu et al., 2016) to simulate the global patterns of ecosystem structure and function to reflect the biodiversity has been used at a global level. But these models are generally coarse and are not able to capture the spatial variability of the biodiversity distribution. An innovative work was done by Roy et al. (2012) to model the spatial distribution of biodiversity in Indian landscape in a GIS based model using remote sensing and ground based inputs. But this approach is scale dependent and also has some limitations to address the spatial distribution of biodiversity at high resolution and site specific variability in the speciation process.

Hence, there is need for platform independent, open system model architecture with respect to the technological advancements and community participation for continuous upgradations of various scientific algorithms. In this study, we have modeled and prioritized pattern of biological richness through fragmentation and biotic disturbance gradients using spatial biodiversity model (SBM) in R programming platform ( $\mathrm{R}$ Development Core Team, 2015) for conservation priority and other management decision. The SBM was successfully applied in similar landscape of Uttarakhanda State of India by Singh et. al., 2017 as a platform independent solution using open system architecture.

\footnotetext{
${ }^{*}$ Corresponding author
} 


\section{MATERIALS AND METHODS}

\subsection{Study site}

The study site is located in the western Nepal and stretched between $28^{\circ} 04^{\prime} 20^{\prime \prime}$ and $28^{\circ} 47^{\prime} 03^{\prime \prime} \mathrm{N}$ and $83^{\circ} 07^{\prime} 00^{\prime \prime}$ and $84^{\circ} 42^{\prime} 40^{\prime \prime}$ E having geographical area of $6,042 \mathrm{Sq}$. $\mathrm{km}$. The altitude of the landscape have an extreme topographic variation

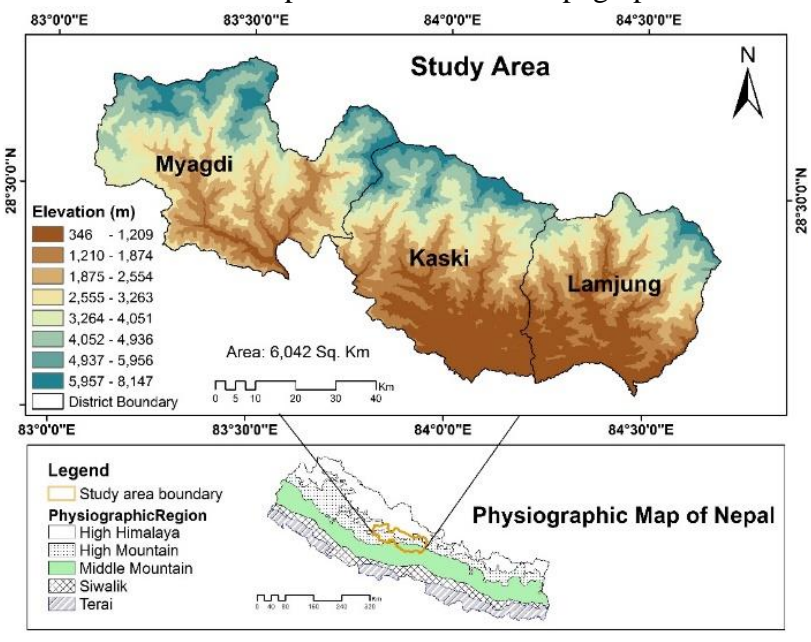

Figure 1. Location of Study Area. (ASTER GDEM 2011 and DFRS 2015)

ranging from $346 \mathrm{~m}$ in south to $8,147 \mathrm{~m}$ in the North. It consists of world's deepest gorge, the Kali Gandaki Gorge (6967 m deep). Fig. 1 represents the area selected for the study. Out of 19 districts under Chitwan-Annapurna Landscape (CHAL), current research site is in 3 districts viz: Myagdi, Kaski and Lamjung districts. The CHAL is a priority due to the urgency of conserving hydrological flows in the major river basin and of creating north-south corridors for seasonal migrations. In 1999, the CHAL was identified as a conservation landscape to maintain north-south ecological connectivity between Chitwan National Park (CNP) in the south and Annapurna Conservation Area (ACA) in the north. The landscape depicts high diversity of plants and is currently facing threats of degradation due to overexploitation of natural resources as a result of anthropogenic pressure (Silwal et. al., 2018). There hasn't conducted similar study yet. Hence, the landscape is selected to characterize biological diversity for conservation prioritization and management decision.

\subsection{Datasets and model}

This study has utilized satellite Remote Sensing data, non-spatial data and ancillary data to generated vegetation type maps, forest fragmentation maps, disturbance maps, and biological richness maps in $\mathrm{R}$ statistical computing environment. The spatial biodiversity model (SBM) developed for similar landscape of Uttarakhanda, India was used in this study. Geospatial analysis was carried out in R, ArcMAP, ENVI and ERDAS IMAGINE.

\subsubsection{Satellite Remote Sensing Data}

Landsat 8 Operational Land Imager (OLI) images of latest two seasons (April and November 2017) and Advanced Spaceborne Thermal Emission and Reflection Radiometer (ASTER) Global Digital Elevation Model (GDEM) with 30m horizontal resolution were retrieved from USGS earth data portal (NASA/METI/AIST/Japan Space systems, and U.S./Japan ASTER Science Team 2018). Because of specified cloud free data were not available, the best available archived data i.e. below $10 \%$ cloud covered data were used.

\subsubsection{Field inventory data and ancillary data}

The phytosociological data of 86 geo-tagged field sample plots encompassing the different forest strata of Myagdi, Kaski and Lamjung districts was used for validation of the output of the study. The field inventory was carried and phytosociological data was generated for forest carbon assessment in CHAL, Nepal (ICIMOD 2016). The road network and settlement locations was created from OpenStreetMap using public participation on web. Census data was retrieved from https://geonode.wfp.org.

\subsection{Model description and flowchart}

The Spatial Biodiversity Model (SBM) established by Singh, et al. (2017) for Uttarakhand state of India was executed using R statistical computing environment which allows to include more user defined indices as per the requirements of the study landscape (R Development Core Team, 2015). The model has four different components i.e. (i) Input: Primary and secondary data sets e.g. vegetation types map derived from multi-season satellite data (Landsat $8 \mathrm{OLI}$ ), socioeconomic data e.g. road network, settlement locations, census data etc., field sample plot species data, DEM from ASTER GDEM data and user defined additional landscape parameters e.g. kernel size, vegetation type classes etc. (ii) Spatial Biodiversity Model (SBM): It is core engine having two level of data processing. Level 1 data processing includes computation of spatial landscape parameter and indices and terrain complexity parameters. Level-2 data processing includes derivation of Disturbance Index (DI) map using multi-criteria decision analysis and sensitivity analysis. (iii) Changing process: Output of DI, terrain complexity (TC), species richness (SR), biodiversity value (BV) and ecosystem uniqueness (EU) was used as input parameters to derive Biological Richness (BR) map of study area. (iv) Output validation: The validation was carried out based on spatial correlation method using field sample plot data.

Multi-criteria decision making (MCDM) and a wide range of related analytical techniques offer a variety of decision making processes to expose and integrate choices with available MCDM methods in order to solve "real-world" GIS-based planning and management problems (Karnatak et al., 2007). In this study, spatial landscape modelling approach was adopted based on highly suitable spatial landscape indices namely fragmentation (edge index), patchiness, porosity, interspersion, juxtaposition, biotic interference (road, settlement), population density, species richness, ecosystem uniqueness and biodiversity values using open source and platform independent environment. A spatial model incorporating ground based biodiversity attributes of the landscape elements, vegetation types/LULC patterns, disturbance regimes of the landscape and terrain complexity have been used to delineate the spatial pattern of BR. Overall research flowchart is presented in fig. 2 .

\subsubsection{Spatial landscape indices}

The application of the spatial landscape indices is to quantify landscape pattern to reflect its capability to support specific ecosystem functions. Distribution of biodiversity is the function of the climate, topography and the external factor in the region. If topography and climate remain constant, variability in a landscape influences the distribution of biodiversity in space in which biotic interference plays vital role. Spatial indices provide a computational environment to scale up the observation of local impacts to regional level. It also allow to process and analyse 


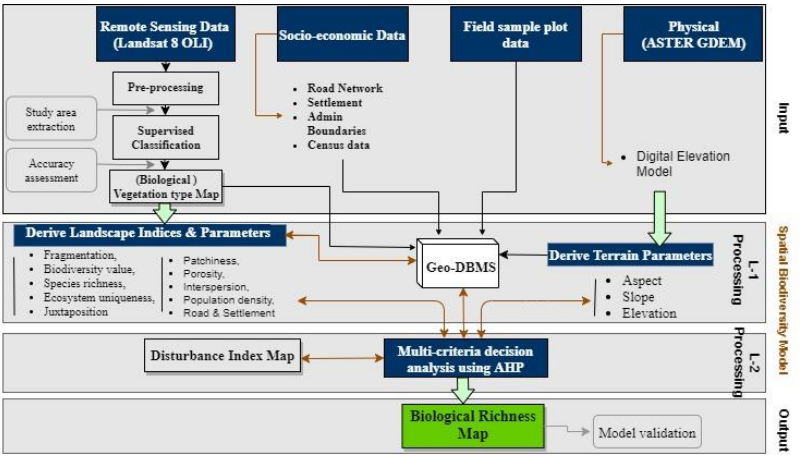

Figure 2. The flowchart to characterized biological diversity using SBM in Nepal Himalaya

effect at a scale which is relevant from the human prospective of valuation and management.

The suitability of the indices i.e. fragmentation, patchiness, porosity, interspersion, juxtaposition, human disturbance, population density, terrain complexity, species richness, ecosystem uniqueness and biodiversity value was based on the evaluation of the importance in biodiversity distribution derived from available relevant literature. Spatial biological richness modelling was carried out for CHAL landscape of Nepal using landscape indices and it was first and historic work in this domain till date. The suitable spatial indices was designated and implemented using $\mathrm{R}$ programming language and statistical computing environment.

\subsubsection{Analytic hierarchy process}

Analytic hierarchy process (AHP) is a decision-making technique utilized for solving complex problems, with many parameters of interrelated objectives or concerned criteria (Rimba et al., 2017). Based on separability analysis of different communities in various vegetation types, associated topographic variability, and socio-economic parameters, a knowledge base of weightages for computation of landscape indices e.g. juxtaposition is developed by normalizing it using AHP (Chen et al., 2013; Karnatak et al., 2007; Prakash, Barua, 2015; Saaty, 1977). The developed model is run after parameterizing the above mentioned inputs (Fig. 2) to generate the various landscape indices required for level-2 processing.

The level-2 data processing of the model includes derivation of DI map using AHP based multi-criteria decision analysis for generation of BR map. At this stage, the model derives fragmentation (edge index), patchiness, porosity, interspersion, juxtaposition, human disturbance (Euclidean distance: road, settlement) and population density as landscape parameters. However, additional user defined parameters can also be included based on study area and availability of data sets. The linear combination of weights and landscape parameters are used to compute DI of study area. The model also computes the variability in terrain complexity using parameters such as slope, aspect and elevation which are derived from ASTER GDEM. As an intermediate result, the DI is computed via linear additive method which is given below:

$D I=F r \times W t+P a \times W t+P r \times W t+I r \times W t+J t \times$

$W t+E d \times W t+P d \times W t$

Where, $\mathrm{W}_{\mathrm{t}}(\mathrm{t}=0-1.0)$ are the weightages computed through AHP.

In the next level of processing, the corresponding normalized weights for each landscape parameter are derived using AHP.
Finally, the BR map is computed via linear additive method:

$$
B R=T C \times W t+S R \times W t+E U \times W t+B V \times W t+D I \times
$$$$
\mathrm{Wt}
$$

where, $\mathrm{W}_{\mathrm{t}}(\mathrm{t}=0-1.0)$ are the weightages computed through AHP.

According to Equation (2), BR input parameters have been selected based on the study objectives, data availability and spatial scale as the base parameter for the model. Moreover, there is a facility in SBM to include new parameters, as per user requirement. Thereafter, all judgments have been made by the decision maker and all pairwise comparison matrices have been determined to quantify AHP process. In order to derive a significant interpretation of the consistency ratio, the threshold value of evaluation criteria was computed following Saaty's (1980) principle.

\subsection{Pre-processing satellite images}

Layer stacking is the process of "stacking" images from the same area together in order to form a multilayer image and spectrally image enhancement. For layer stacking, of the OLI sensor with individual bands from 2 to 7 was extracted and stacked respective row and path spectral bands. The study area is present in zone 45 of Universal Transverse Mercator (UTM) coordinate system, World Geodetic System (WGS) 84.

Image enhancement is the technique by which the low contrast of satellite images is improved to make the image more interpretable. 'Standard deviation stretch' is the algorithm to enhance image contrast and the spectral behavior of the satellite imageries. The magnitude of the enhancement depends on the standard deviation value defined by the analyst. The 'Standard deviation stretch' algorithm was used to improve the image contrast to identify the classes (Hashimoto et al. 2011). An interval value between -2.5 to +2.5 standard deviations from the mean of the existing pixel values was used in this study. This stretched the values to the complete range of output screen values. In addition, the study used the contrast brightness utility of ERDAS IMAGINE to enhance visual details of the satellite images.

\subsection{Vegetation types classification approach}

The vegetation type can be defined as an embodiment of unique physiognomy, structure, and floristics (intrinsic factors), influenced by the climate, topography, and anthropogenic factors (extrinsic factors). Champion, Seth's (1968) classification scheme follows a hierarchical approach wherein climatically driven forest ecosystems systems with distinct physiognomy and phenology are primarily classified as type groups. These type groups are further subdivided into sub- groups based on dominant compositional patterns and region and location specific formations controlled by edaphic and disturbance conditions. Stainton (1972) recognized 35 forest types on the basis of detailed floristic studies and classified into 10 major groups in Nepal. The existing classification systems precisely used ground data in deciphering the patterns of species assemblages but did not provide the explicit spatial boundaries of these assemblages. Such spatial explicit boundaries of vegetation types are important for studying the patterns of vegetation diversity and long-term monitoring. The delineation of such boundaries for larger spatial extents based on geospatial tools and field information have become time and cost effective. Two-season Landsat 8 OLI images of 2017 were utilized optimally to map the vegetation types depending on the forest 
phenology, i.e., leaf fall and peak growth seasons. Satellite data pertaining to the time windows of November and April were used to take into account the phenological variations required for delineation of different vegetation types.

The on-screen visual interpretation technique using maximum likelihood classification (MLC) and support vector machine (SVM) classifiers were selected for the land cover classification of OLI data. The Google Earth Map and altitude zone maps were used to define classes. Wherever necessary, field data were used to delineate the vegetation type and locale-specific classes. The MLC has been the most popular parametric classifier used for remote sensing data classification (Foody et al. 1997; Jia et. al., 2011). The MLC assumes that a hyper-ellipsoid decision volume can be used to approximate the shape of the data clusters. Moreover, for a given unknown pixel, the probability of membership in each class is calculated using the mean feature vectors of the classes, the covariance matrix and the prior probability (Duda, Hart, 1973). The unknown pixel is considered to belong to the class with the maximum probability of membership. The SVM classifier is the most widely used nonparametric statistical learning classifier with no assumptions made regarding the underlying data distribution. This method typically performs better in land cover classification studies (Pal, Mather, 2005; Pal, Foody, 2012, Foody, Mathur, 2004). The surface reflectance value of bands 2, 3, 4, 5, 6 and 7 of OLI data were used for land cover classification using MLC and SVM classifier.

\subsection{Vegetation types classification accuracy}

To validate the land cover classification performance using OLI data, the classification results using the MLC and SVM classifiers were assessed via visual observations and quantitative classification accuracy indicators. Randomly selected sample pixels were used to quantitatively assess the land cover classification accuracy. The total sample pixels used for the classification accuracy estimation were 6150 pixels for forest, 3607 pixels for snow, 1580 pixels for water body, 386 pixels for built up area, 278 pixels for agriculture, 680 pixels for barren land and 1679 pixels for reject class e.g. shadow and cloud. The overall classification accuracy, producer's accuracy, user's accuracy and Kappa statistics were then estimated for quantitative classification performance analysis (Congalton, Green, 1999, Foody 2013, Tso, Mather, 2001, Foody 2009).

\subsection{Model validation}

The spatial BR map can be validated with ground based species diversity information (Shannon-Wiener index) of the study landscape. The phytosociological data collected by ICIMOD as part of Forest Carbon Assessment in CHAL landscape project using RS and GIS (ICIMOD, 2016) was used to compute the Shannon-Wiener index (Shannon, 1948) for individual field plot (86permanent sample plots representing cold alpine semi-desert to sub-tropical humid climates) of $15.45 \mathrm{~m}$ radius plots for tree, $5.64 \mathrm{~m}$ radius sub-plots for saplings, $2.82 \mathrm{~m}$ radius sub- plot for shrubs and $1 \mathrm{~m}$ radius sub-plot for counting regeneration/seedling. Correction for the slope was applied whenever required. Shannon-Wiener index values was plotted against BR map values and correlation coefficient for herbs, shrubs and tree diversity was observed. The higher the $\mathrm{R}^{2}$ values, the better the model fits user's field data. The regression curve represents the actual condition reflecting variation in the compositional structure of the plant species communities with the varying levels of the BR index map.

\section{RESULTS}

\subsection{Vegetation types and land use}

The sum total of vegetation types and land use for 2017 consist of 13 classes viz: Tropical Moist Deciduous Forest, Subtropical Broadleaved Hill Forest, Sub-Tropical Pine Forest, Montane Wet Temperate Forest, Himalayan Moist Temperate Forest, Subalpine Forest, Dry Alpine Scrub, Barren land, Agriculture, Built up area and Settlement, Waterbody, Snow and reject class (Shadow and Cloud). The predominance of forest land is evident, constituting $50.80 \%$ of the total geographical area followed by snow $(17.11 \%)$, agriculture (15.22\%), barren land (15.09\%), settlement $(0.99 \%)$, waterbody $(0.58 \%)$ and reject class $(.20)$ (Fig. 3).

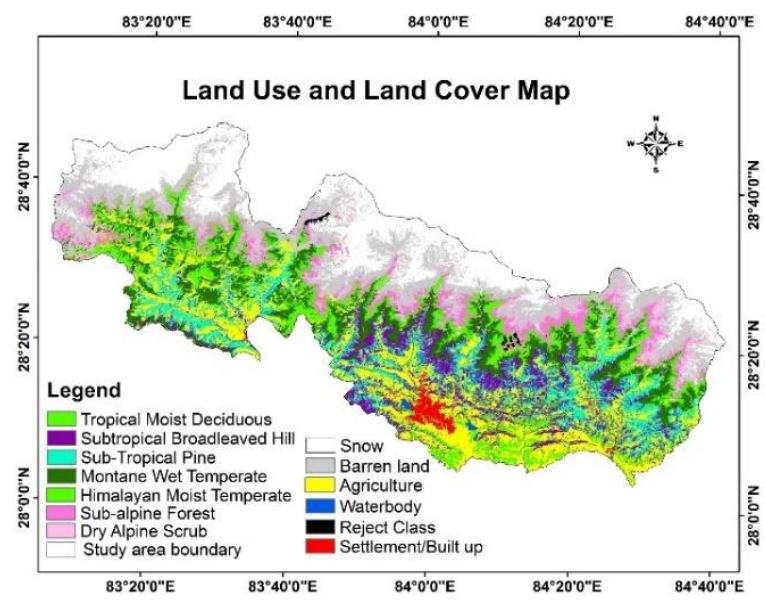

Figure 3. Vegetation types and land use map of 2017

\subsection{Species composition in forest types}

Tropical Moist Deciduous Forest is distributed in the southern belt of Lamjung and Kaski districts along the Siwaliks where dominated species was Shorea robusta. The su-btropical broad leaved forests is dominated by Schima wallichii and Castanopsis indica and associate species are Phyllanthus emblica, Lagerstroemia parviflora etc. (Silwal et. al., 2018). Subtropical pine forests are characterized by Chir pine (Pinus roxburghii). In Monte Wet Temperate Forest, dominated species in lower mountain region are Quercus lamellose, Castanopsis tribuloides, Lauraceae spp. whereas Quercus semecaprpifolia, Acer spp. and Rhododendron spp. dominated in the upper area. Pinus wallichiana, Abies spectabilis and Tsuga dumosa dominated in the Himalayan Moist Temperate Forest. Abies spectabilis, Betula utilis and Rhododendron species are the key species of the SubAlpine Forest. Common species of the Dry Alpine Scrub are Juniperus spp. and Rhododendron spp in the study landscape.

\subsection{Forest Fragmentation index}

The derived map is representing forest and non-forest area. The moving window size of $11 \times 11$ pixel was used to model fragmentation map using $\mathrm{R}$ statistical computing platform. The computed forest fragmentation (edge index) map (Fig. 4) has integer values ranging between 0 and 100. Based on natural breaks classification, fragmentation map is categorized into 4 classes as low (dense forest), moderate, high and very high including non-forest area to quantify forest habitat fragmentation and increase in forest edge within the study area. Low class corresponds to dense forest and very high class is highly fragmented landscape. Shrinkage of core forest patches is the biological diversity indicator of increasing forest degradation 
and fragmentation. The highest percentage of geographical area is covered by dense forest and followed by moderate fragmentation, high fragmentation and highly fragmented forest area.

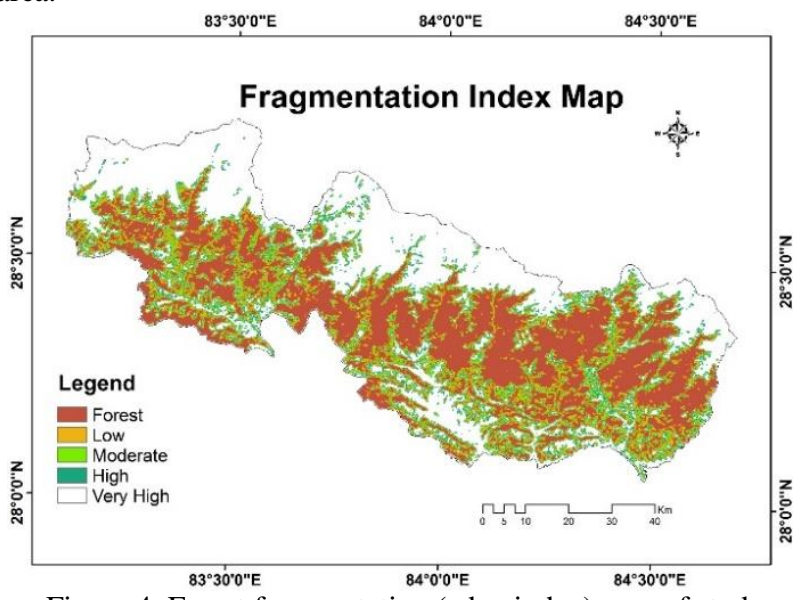

Figure 4. Forest fragmentation (edge index) map of study

\subsection{Disturbance index}

The prediction of the spatial pattern of landscape disturbance map is an important requirement for characterizing biological diversity. The computed DI map (Fig. 5) has integer pixel values ranging from 0 to 100 . On the basis of the natural breaks classification, the DI map is categorized as forest, low, moderate, high and very high for identifying the spatial characteristics and extent of anthropogenic disturbance affecting the forest in study area. The forest corresponds to very low disturbed class and very high is highly disturbed region. The derived DI map is depicting the regions of high disturbance as well as forest edges. DI map showed that highest percentage of geographical area is under low disturbance class and followed by moderate disturbance class, high disturbance class and very high disturbance class respectively.

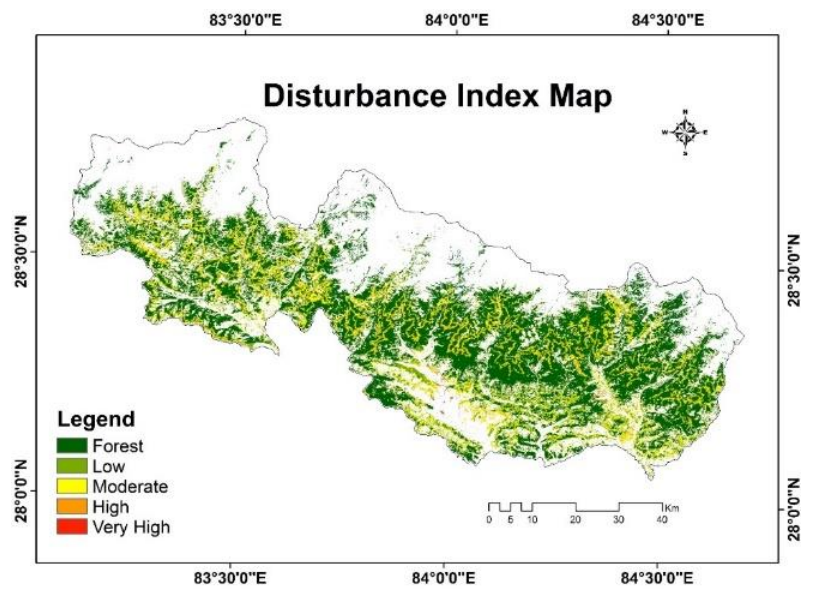

Figure 5. Disturbance index map of study area

\subsection{Biological richness}

The biodiversity value, species richness and ecosystem uniqueness were generated with the field sample plot data and knowledgebase. The terrain complexity data was computed as weighted function of aspect, slope, elevation and their weighted spatial variability. The BR map is computed as linear weighted additive method of biodiversity value, species richness, terrain complexity, ecosystem uniqueness and DI.

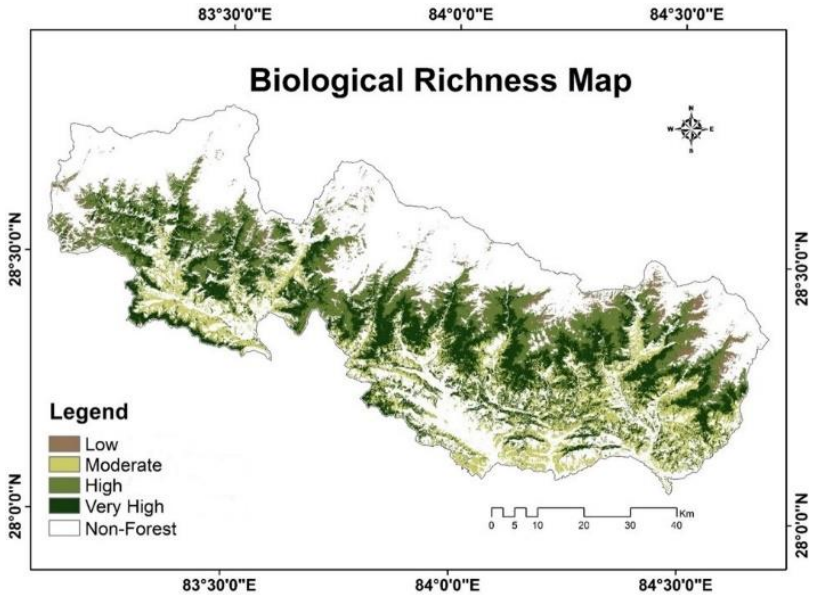

Figure 6. Biological richness map of study area

The computed BR map has integer pixel values ranging from 0 to 100 . Based on natural breaks classification, BR map (Fig. 6) are categorized into 4 classes as low, moderate, high and very high including non-forest area to quantify the biodiversity rich area.

The BR map predicted highest area under very high BR class, followed by high BR class, moderate BR class and low BR class. Statistics of percentage of area distribution is depicted in bar graph (Fig. 7)

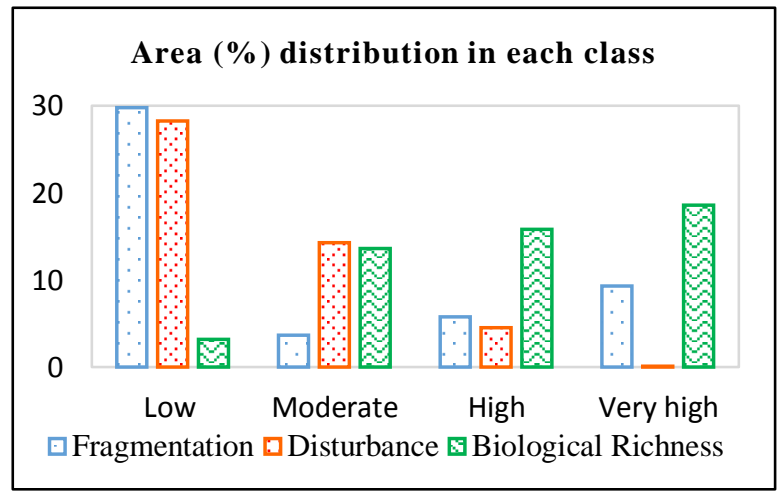

Figure 7. Area (\%) statistics of forest fragmentation, disturbance and biological richness in four different classes

\subsection{Accuracy assessment}

The overall accuracy of the vegetation type classification, assessed on the basis of field sample plot data was $82.61 \%$ and Kappa Statistics of 0.8013.The spatial BR map is validated with ground based species diversity information (Shannon-Wiener index and Margalef diversity index) of the study area. The phytosociological data collected from field as part of Forest Carbon Assessment of CHAL level using RS\&GIS (ICIMOD 2016) was used to compute the Shannon-Wiener index (Shannon, 1948) and Margalef diversity index (Margalef, 1958) for individual field plot (86 sample plots representing the different ecosystem of the study area). The Shannon-Wiener index values and Margalef's diversity index value have been plotted against BR map values separately and the correlation coefficients for the tree diversity have been observed to be 0.64 and 0.56 as shown in Fig. 8 (a) and (b) respectively. 


\section{DISCUSSION}

Shrinkage of core forest patches is an indicator of increasing fragmentation. The loss of biodiversity has been attributed to the destruction of habitat, isolation of fragments of formerly contiguous habitats and edge effects within a boundary zone between forest and deforested areas. With increase in the anthropogenic degradation of the natural areas, there is a need for periodic and rapid assessment of the biodiversity distribution across the landscape. CHAL is considered significant for biodiversity conservation because of its floristic richness and high level of endemism. A national level study carried by Reddy et al. (2017) show that the land cover legend for 2014 is consisting of 21 classes, i.e. tropical dry deciduous sal forest, tropical moist deciduous sal forest, subtropical broad-leaved forest, subtropical pine forest, lower temperate broad leaved forest, upper temperate broad leaved forest, lower temperate mixed broad leaved forest, upper temperate mixed broad leaved forest, temperate needle leaved forest, subalpine forest, plantations, tropical scrub, subtropical scrub, temperate scrub, alpine scrub, grassland, agriculture, water bodies, barren land and settlements. Current study assesses 13 LULC classes including 7 forest types where about $50 \%$ area is under forest in the landscape. According to the study of Reddy et al., 2017, the predominance of agricultural land is evident, constituting $28.2 \%$ of the total geographical area followed by forest $(26.8 \%)$. The overall loss of dense forest is high as compared to open forest. The loss of an area of $1768 \mathrm{Km}^{2}(6.9 \%)$ of dense forest was found from 1975 to 2014 in Nepal (Reddy et al., 2017). Tropical deciduous sal forests show more spatial changes followed by Subtropical broad leaved forest from 1975 to 2014 in Nepal. Regarding the historical fragmentation, the total number of forest patches increased from 1930 to 2014. (Reddy et al., 2017). Current research finding shows that more than $18 \%$ forests of the landscape is affected by anthropogenic disturbances, which in turn affect the biological richness of the landscape. This study found that the main cause of disturbance in forest is anthropogenic activities i.e. grazing, lopping, felling for timber extraction, forest fire, forest road and encroachment in the study landscape which is in line with DFRS, 2015. This has resulted in the fragmentation of the landscape and the loss of many endemic species. The progressive fragmentation might have significant ecological implications for species dependent on interior regions of forest patches (Echeverri'a et al., 2006).

\section{CONCLUSION}

Proper documentation of biological resource is essential for conservation and sustainable use of natural wealth in the benefit of mankind (Tangley, 1990). This study provides spatial information on fragmentation, disturbance and biological richness of study site. Approximately 50\% area is under forest which ensure high potential of biodiversity in the landscape. Fragmentation and disturbance area under high to very high class is about $15 \%$ and $5 \%$ respectively and still greater than $18 \%$ area is under BR area.

\section{RECOMMENDATION}

The existing databases on floristic and detailed ecological and edaphic databases relating to selected few study areas are not geo-spatially linked. The absence of a spatially linked database of plant population structure, population dynamics, and abiotic driving and driven variables and other limiting factors makes it difficult to characterize, monitor and conserve species. Nepal is representative of the land cover diversity in the Hindu Kush Himalayas region. The HKH region has been identified as a blank spot for data by the Inter-Governmental Panel on Climate Change, indicating the need to develop regional database and sharing mechanisms (Sharma et. al., 2010). In this context, this study provides spatial information on fragmentation, disturbance and biological richness of study site. Result of this study is expected to contribute in systematic inventory, conservation prioritization and management decision of forest resources in the study landscape. Finally, up scaling of the similar research covering larger extent in Nepal and beyond the boarder is recommended.

\section{ACKNOWLEDGEMENTS}

The first author gratefully acknowledges Centre for Space Science and Technology Education in Asia and the Pacific (CSSTEAP) for financial support during the study. The authors are thankful to the Director, Indian Institute of Remote Sensing, ISRO and CSSTEAP Dehradun, India for his support during the study. The authors are thankful to ICIMOD for providing the field data.

\section{REFERENCES}

Behera, M.D. and Roy, P.S., 2010: Assessment and validation of biological richness at landscape level in part of the Himalayas and Indo-Burma hotspots using geospatial modeling approach. Journal of the Indian Society of Remote Sensing, 38(3), pp.415-429.

Beltrán, B.J., Franklin, J., Syphard, A.D., Regan, H.M., Flint, L.E. and Flint, A.L., 2014: Effects of climate change and urban development on the distribution and conservation of vegetation in a Mediterranean type ecosystem. International Journal of Geographical Information Science, 28(8), pp.1561-1589.

Beniston, M., 2003: Climatic change in mountain regions: a review of possible impacts. In Climate variability and change in high elevation regions: Past, present \& future (pp. 5-31). Springer, Dordrecht.

Champion, S.H. and Seth, S.K., 1968. A revised survey of the forest types of India. A revised survey of the forest types of India.

Chen, Y., Yu, J. and Khan, S., 2013: The spatial framework for weight sensitivity analysis in AHP-based multi-criteria decision making. Environmental modelling \& software, 48, pp.129-140.

Chitale, V., Silwal, R. and Matin, M., 2018: Assessing the Impacts of Climate Change on Distribution of Major NonTimber Forest Plants in Chitwan Annapurna Landscape, Nepal. Resources, 7(4), p.66.

Congalton, R.G. and Green, K., 1999: Assessing the accuracy of remotely sensed data: principles and practices. CRC press.

DFRS, 2015: State of Nepal's Forests. Forest Resource Assessment (FRA) Nepal, Department of Forest Research and Survey (DFRS). Kathmandu, Nepal.

Duda, R.O. and Hart, P.E., 1973: Pattern recognition and scene analysis.

Ebi, K.L., Woodruff, R., von Hildebrand, A. and Corvalan, C., 2007: Climate change-related health impacts in the Hindu KushHimalayas. EcoHealth, 4(3), pp.264-270.

Echeverría, C., Coomes, D., Salas, J., Rey-Benayas, J.M., Lara, A. and Newton, A., 2006: Rapid deforestation and fragmentation 
of Chilean temperate forests. Biological conservation, 130(4), pp.481-494.

Foody, G.M. and Mathur, A., 2004: A relative evaluation of multiclass image classification by support vector machines. IEEE Transactions on geoscience and remote sensing, 42(6), pp.1335-1343.

Foody, G.M., 2009: Classification accuracy comparison: hypothesis tests and the use of confidence intervals in evaluations of difference, equivalence and noninferiority. Remote Sensing of Environment, 113(8), pp.16581663.

Foody, G.M., 2013: Ground reference data error and the misestimation of the area of land cover change as a function of its abundance. Remote Sensing Letters, 4(8), pp.783-792.

Foody, G.M., Lucas, R.M., Curran, P.J. and Honzak, M., 1997: Mapping tropical forest fractional cover from coarse spatial resolution remote sensing imagery. Plant Ecology, 131(2), pp.143-154.

Gordon, A., Langford, W.T., Todd, J.A., White, M.D., Mullerworth, D.W. and Bekessy, S.A., 2011: Assessing the impacts of biodiversity offset policies. Environmental Modelling \& Software, 26(12), pp.1481-1488.

Halkos, G.E. and Tzeremes, N.G., 2010: Measuring biodiversity performance: A conditional efficiency measurement approach. Environmental Modelling \& Software, 25(12), pp.1866-1873.

Harfoot, M.B., Newbold, T., Tittensor, D.P., Emmott, S., Hutton, J., Lyutsarev, V., Smith, M.J., Scharlemann, J.P. and Purves, D.W., 2014: Emergent global patterns of ecosystem structure and function from a mechanistic general ecosystem model. PLoS biology, 12(4), p.e1001841.

Hashimoto, N., Murakami, Y., Bautista, P.A., Yamaguchi, M., Obi, T., Ohyama, N., Uto, K. and Kosugi, Y., 2011: Multispectral image enhancement for effective visualization. Optics express, 19(10), pp.9315-9329.

ICIMOD, 2016. Forest Carbon Assessment in ChitwanAnnapurna Landscape. Field Data, International Centre for Integrated Mountain Development (ICIMOD), Kathmandu, Nepal.

Immerzeel, W.W., Van Beek, L.P. and Bierkens, M.F., 2010 Climate change will affect the Asian water towers. Science, 328(5984), pp.1382-1385.

Jia, K., Wu, B., Tian, Y., Zeng, Y. and Li, Q., 2011: Vegetation classification method with biochemical composition estimated from remote sensing data. International journal of remote sensing, 32(24), pp.9307-9325.

Karnatak, H.C., Saran, S., Bhatia, K. and Roy, P.S., 2007: Multicriteria spatial decision analysis in web GIS environment. Geoinformatica, 11(4), pp.407-429.

Kersebaum, K.C., Boote, K.J., Jorgenson, J.S., Nendel, C., Bindi, M., Frühauf, C., Gaiser, T., Hoogenboom, G., Kollas, C., Olesen, J.E. and Rötter, R.P., 2015: Analysis and classification of data sets for calibration and validation of agro-ecosystem models. Environmental Modelling \& Software, 72, pp.402-417.
Maikhuri, R.K., Rao, K.S. and Semwal, R.L., 2001: Changing scenario of Himalayan agroecosystems: loss of agrobiodiversity, an indicator of environmental change in Central Himalaya, India. Environmentalist, 21(1), pp.23-39.

Margalef, D. R. 1958: Information theory in ecology. Gen. Syst. 3:36-71

Myers, N., Mittermeier, R.A., Mittermeier, C.G., Da Fonseca, G.A. and Kent, J., 2000: Biodiversity hotspots for conservation priorities. Nature, 403(6772), p.853.

NASA/METI/AIST/Japan Space systems, and U.S./Japan ASTER Science Team 2018: ASTER Global Digital Elevation Model NetCDF V003. NASA EOSDIS Land Processes DAAC. Accessed 2018-01-23 from https://doi.org/10.5067/ASTER/ASTGTM_NC.003.

Orsi, F., Church, R.L. and Geneletti, D., 2011: Restoring forest landscapes for biodiversity conservation and rural livelihoods: A spatial optimisation model. Environmental Modelling \& Software, 26(12), pp.1622-1638.

Pal, M. and Foody, G.M., 2012: Evaluation of SVM, RVM and SMLR for accurate image classification with limited ground data. IEEE Journal of Selected Topics in Applied Earth Observations and Remote Sensing, 5(5), pp.1344-1355.

Pal, M. and Mather, P.M., 2005: Support vector machines for classification in remote sensing. International Journal of Remote Sensing, 26(5), pp.1007-1011.

Prakash, C. and Barua, M.K., 2015: Integration of AHP-TOPSIS method for prioritizing the solutions of reverse logistics adoption to overcome its barriers under fuzzy environment. Journal of Manufacturing Systems, 37, pp.599-615.

Prasad, P.R.C., Rajan, K.S., Dutt, C.B.S. and Roy, P.S., 2010: A conceptual framework to analyse the land-use/land-cover changes and its impact on phytodiversity: a case study of North Andaman Islands, India. Biodiversity and conservation, 19(11), pp.3073-3087.

R Development Core Team, 2015. R:, 2015. A Language and Environment for Statistical Computing. R Foundation for Statistical Computing. Vienna, Austria. URL. http://www.Rproject.org/.

Ramesh, K.V. and Goswami, P., 2007: Reduction in temporal and spatial extent of the Indian summer monsoon. Geophysical Research Letters, 34(23).

Reddy, C.S., Pasha, S.V., Satish, K.V., Saranya, K.R.L., Jha, C.S. and Murthy, Y.K., 2018: Quantifying nationwide land cover and historical changes in forests of Nepal (1930-2014): Implications on forest fragmentation. Biodiversity and conservation, 27(1), pp.91-107.

Romme, W.H. and Knight, D.H., 1982: Landscape diversity: the concept applied to Yellowstone Park. BioScience, 32(8), pp.664670.

Rimba, A., Setiawati, M., Sambah, A. and Miura, F., 2017: Physical flood vulnerability mapping applying geospatial techniques in Okazaki city, Aichi prefecture, Japan. Urban Science, 1(1), p.7. 
Roy, A., Bhattacharya, S., Ramprakash, M. and Kumar, A.S., 2016: Modelling critical patches of connectivity for invasive Maling bamboo (Yushania maling) in Darjeeling Himalayas using graph theoretic approach. Ecological modelling, 329, pp.77-85.

Roy, P.S. and Tomar, S., 2000: Biodiversity characterization at landscape level using geospatial modelling technique. Biological conservation, 95(1), pp.95-109.

Roy, P.S., Roy, A. and Karnataka, H., 2012: Contemporary tools for identification, assessment and monitoring biodiversity. Tropical Ecology, 53(3), pp.261-272.

Shannon, C.E., 1948: A mathematical theory of communication. Bell system technical journal, 27(3), pp.379-423.

Saaty, T.L., 1977: A scaling method for priorities in hierarchical structures. Journal of mathematical psychology, 15(3), pp.234281.

Saaty, T.L., 1980: The analytic hierarchy process McGrawHill. New York, 324.

Sharma, E., Chettri, N. and Oli, K.P., 2010: Mountain biodiversity conservation and management: a paradigm shift in policies and practices in the Hindu KushHimalayas. Ecological Research, 25(5), pp.909-923.

Shrestha, D., Singh, P. and Nakamura, K., 2012: Spatiotemporal variation of rainfall over the central Himalayan region revealed by TRMM Precipitation Radar. Journal of Geophysical Research: Atmospheres, 117(D22).

Silwal, R., Baral, S.K. and Chhetri, B.K., 2018. Modeling taper and volume of Sal (Shorea robusta Gaertn. f.) trees in the western Terai region of Nepal. Banko Janakari, pp.76-83.

Silwal, R., Maharjan, S., Shrestha, B., Chitale, V. and Murthy, M., 2018: An Innovative Approach for Understanding the Patterns in Distribution and Extraction of Non-Timber Forest
Products in Chitwan Annapurna Landscape, Nepal. Indian For, 144, pp.243-251.

Singh, H., Garg, R.D., Karnatak, H.C. and Roy, A., 2018: Spatial landscape model to characterize biological diversity using $\mathrm{R}$ statistical computing environment. Journal of environmental management, 206, pp.1211-1223.

Stainton, J.D.A., 1972. Forests of Nepal. Hafner Publishing Company.

Tangley, L., 1990: Cataloging costa rica's diversity. BioScience, 40(9), pp.633-636.

Tso B, Mather PM. 2001 Classification methods for remotely sensed data. London: Taylor and Francis.

Turner, M.G., 1987: Landscape Heterogeneity and Disturbance. Springer-Verlag, New York.

Wilson, M.C., Chen, X.Y., Corlett, R.T., Didham, R.K., Ding, P., Holt, R.D., Holyoak, M., Hu, G., Hughes, A.C., Jiang, L. and Laurance, W.F., 2016: Habitat fragmentation and biodiversity conservation: key findings and future challenges.

Yu, L., Belyazid, S., Akselsson, C., van der Heijden, G. and Zanchi, G., 2016: Storm disturbances in a Swedish forest-A case study comparing monitoring and modelling. Ecological modelling, 320, pp.102-113.

Zhai, D.L., Cannon, C.H., Dai, Z.C., Zhang, C.P. and Xu, J.C., 2015: Deforestation and fragmentation of natural forests in the upper Changhua watershed, Hainan, China: implications for biodiversity conservation. Environmental monitoring and assessment, 187(1), p.4137.

Zomer, R.J., Trabucco, A., Metzger, M.J., Wang, M., Oli, K.P. and $\mathrm{Xu}$, J., 2014: Projected climate change impacts on spatial distribution of bioclimatic zones and ecoregions within the Kailash Sacred Landscape of China, India, Nepal. Climatic change, 125(3-4), pp.44. 